\title{
Viriatus Hispaniae Romulus
}

\author{
Raquel lópez Melero *
}

Para el historiador latino Floro es Viriato la figura más importante del medio indígena hispánico en la fase de su resistencia al imperialismo romano: si la fortuna lo hubiera permitido, él habría sido el Rómulo de Hispania afirma '. Floro no duda en asumir ciertos elementos de la tradición biográfica de Viriato que no han parecido fidedignos a todos los historiadores modernos ${ }^{2}$ y tampoco carece de una retórica formal potencialmente recreadora del contenido, pero su obra tiene un designio historiográfico mucho más que literario, y las puntualizaciones de carácter político que se contienen en ella suelen ser certeras ${ }^{3}$. Por más que los

* Departamento de Prehistoria e Historia Antigua, UNED, Madrid.

'Floro 1.33.15: «... si fortuna cessisset, Hispaniae Romulus".

2 Floro ibid.: «... ex venatore latro, e latrone subito dux atque imperator". Floro, que escribe a finales del reinado de Adriano, es uno de los decantadores de la tradición histiográfica grecorromana, donde se contienen los tópicos más significativos en relación con la persona de Viriato. Sobre el conjunto de las referencias, anteriores o posteriores a la obra de Floro, v. F.H.A. IV, pág. 107 y ss. Cf. Livio, Per. 52: "Viriatus... ex pastore venator, ex venatore latro"; Veleyo Patérculo 2.1.: "duce latronum Viriatho"; Orosio 5.4.1.: "Viriatus homo pastoralis et latro, primum infestando vias, deinde vastando provincias, postremo exercitus praetorum et consulum Romanorum vincendo".

${ }^{3}$ Véase P. JAL, “Nature et signification politique de l'ouvrage de Florus", Rev. Et. Lat. 1965, págs. 358-383, donde se reivindica la figura del historiador político frente a la de un simple epitomista de Tito Livio. La función peculiar en el pensamiento de Floro que desempeña la oposición "virtus/fortuna" es una prueba de su autonomia en la condición de historiador desde un punto de vista filosófico e ideológico. Cr. A. NOROH, "Virtus and Fortuna in Florus", Eranos, 1952, págs. 111-128. Véase asimismo el trabajo de J. STRAuB, fundamental para conocer la vocación histórico-política de Floro, "Reichsbewusstein und Nationalgefühl in den römischen Provinzen. Spanien und das Imperium Romanum in der Sicht des Florus", Jahrbuch des Römisch-Germanischen Zentralmuseums Mainz, 1978, pág. 186; y el de J. J. SAYAS ABengochea "Municipalización de la Hispania romana. Ideología y Realidad", en Centralismo y Descentralización. Modelos y procesos históricos en Francia y en España, Madrid 1985, pág. 101 y ss. 
detalles sobre las campañas de Viriato que recoge Floro resulten bastante inexactos ${ }^{4}$, la consideración del lusitano como alguien que estuvo a punto de consolidar un "regnum" hispano no tiene por qué parecer descabellada, ni siquiera hiperbólica. No es una pieza necesaria en ese elogio de Roma, exaltación de las conquistas llevadas a cabo entre Rómulo y Augusto, en que se contiene el pasaje ${ }^{5}$; que no contribuye en especial a la "laus Romae" el hecho de que un caudillo bárbaro haya sido privado por la fortuna de la posibilidad de rechazar con eficacia la fuerza conquistadora de esa potencia, creando, además, su propio reino. Diríase que la memoria historiográfica de los Romanos había registrado la guerra de Viriato como una coyuntura singular en que se decidió de un modo un tanto aleatorio la expansión del dominio romano hacia el interior de la Península; y ello en la idea de que, si se hubiera consolidado un poder indígena fuerte, Roma habría tenido que conformarse todo lo más con fijar unas fronteras, debiendo, en consecuencia, reconocer una Hispania independiente.

Es posible que esta idea no fuera universalmente asumida por los Romanos, toda vez que los hechos habían discurrido por la línea de la sumisión y romanización de todo el territorio, resultando verosímil, por otra parte, la capacidad de Roma para vencer cualquier resistencia indígena en la Península cuando se diera la conjunción favorable de una disponibilidad suficiente de tropas y de un general dotado de las cualidades necesarias para comandarlas eficazmente. Desde un punto de vista militar absoluto la empresa de Viriato o de sus eventuales sucesores estaba potencialmente abocada al fracaso, pero el comportamiento de Roma en el caso de las Islas Británicas, por ejemplo, indica que la expansión territorial tenía como móvil principal la explotación económica de las áreas anexionadas, de tal manera que, cuando los beneficios obtenidos en alguna de ellas eran inferiores a los gastos militares requeridos para su efectiva y permanente sumisión, parece que ese territorio perdía interés a los ojos de los romanos, concentrándose en tal supuesto los esfuerzos en salvaguardar, por el procedimiento que se creyera más adecuado, el dominio de las zonas productivas. Incluso el interés personal de algunos gobernadores por aumentar su prestigio realizando operaciones de castigo más o menos exitosas por las áreas indígenas

${ }^{4}$ Hay que admitir que el sumarísimo resumen que aporta Floro de las guerras de Viriato es poco menos que disparatado en su confrontación con el grueso de las fuentes, pero también es cierto que esos errores de minucia no invalidan la semblanza general que hace Floro del personaje.

${ }^{5}$ Cf. P. JaL. Florus, Oeuvres, T. I, pág. XLII. 
periféricas a las tierras sometidas se veía limitado cuando se trataba de poblaciones ya esquilmadas previamente, de las que no se podia obtener un botín que compensara los gastos ${ }^{6}$.

\section{Es en este contexto de primacía de los intereses económicos en el que habría que analizar muy posiblemente el episodio histórico de la paz}

${ }^{6}$ Existe una polémica bien conocida entre aquellos que, como RostovzefF (A Social and Economic History of the Roman Empire, Oxford 1957, vol. I, págs. 13-22), piensan que las conquistas romanas se vieron impulsadas por motivos económicos y los que, como BADIAN (Roman Imperialism in the Late Republic, Oxford 1968, págs. 16-21), niegan que Roma buscara el provecho material en las operaciones de ampliación de sus territorios, indicando que las entradas que de un modo u otro registraba el erario público romano procedentes de las provincias eran aceptadas como una consecuencia obvia del dominio de los territorios correspondientes, pero que no constituian el móvil de las decisiones políticas y militares al respecto.

Por muy irreductibles que parezcan estas dos posiciones, resultan en realidad conciliables, por cuanto que ambas implican una simplificación en el análisis del proceso. Porque no es cierto que Roma se limitara a percibir en las provincias el tributo que habian cobrado sus predecesores en el dominio, los Cartagineses, pues sabemos que se impusieron tribulos nuevos; y sabemos que no sólo hubo explotación sino incluso extorsión hasta unos extremos taies que la propia Roma se vio obligada a establecer un control con la creación en el 171 de un tribunal especial (Cf. Tito Livio, 43.2) y más tarde, en el 149, 122, 81 y 59 a.C., de las leyes Calpurnia de pecuniis repetundis, Acilia Repetundarum, Cornelia Repetundarum y lulia Repetundarum, respectivamente, destinadas todas ellas a fijar la responsabilidad de los magistrados, en especial los provinciales, por abusos económicos sobre sus subordinados, así como las posibilidades de reclamación y satisfacción para éstos. La primera de estas leyes creaba la "quaestio de repetundis", con tribunal permanente, y fijaba el concepto de "crimen repetundarum".

En cuanto al botín de guerra, se aplicó la norma general de despojo de los vencidos en sus cosas y sus personas, siendo frecuente la venta de los enemigos como esclavos; la firma de las paces y tratados de amistad era también ocasión de expolio para los romanos, como indican inequívocamente las fuentes. Con todas las reservas que hay que conceder a este tipo de cálculos, que descansan siempre sobre estimaciones aproximadas, supone R. C. Knapp (Aspects of the Roman Experience in Iberia 206-100 B.C., Valladolid 1977, pág. 165 y ss.) que en el período de tiempo que media entre los años 206 al 169 Roma obtuvo de Hispania un total de 96.400 .000 denarios, correspondientes a tres partidas diferentes: botín de guerra (47.000.000), impuestos (11.400.000) y explotación de las minas (38.000.000). Una cuarta parte de esta cantidad aproximadamente habria sido de beneficio neto, una vez deducidos los gastos correspondientes.

KNAPP recoge todos los datos que directa o indirectamente proporcionan las fuentes sobre estos conceptos, discutiendo oportunamente su valoración. Véase también J. M. BLÁzQUEZ, Historia EConómica de la Hispania Romana, Madrid 1978, pág. 73; G. FATAS, "Un aspecto de la explotación de los indigenas hispanos por Roma: los botines de guerra en la Citerior", Estudios, 1973, pág. 101 y ss. Lo que no se puede cuantificar, porque carecemos de cifras precisas, es el montante de lo obtenido por los gobernadores para su propio peculio en concepto de extorsión o abuso en la recaudación de los tributos, pero debió de ser considerable. Véase R. C. JOLIFFE, Corruption in Roman Administration, Chicago 1919; C. VENTURINI, “La repressione degli abusi dei magistrati romani ai danni delle popolazioni soggete fino alla lex Calpurnia del 149 a.C.", Bollettino dell'Istituto di Diritto Romano LXII, 1969, pág. 19-87; E. Gruen, Roman Politics and the Criminal Courts 149-78 B.C. Cam- 
de Serviliano y el subsiguiente de la guerra de Servilio Cepión, ambos estrechamente relacionados entre sí. Las actuaciones fundamentales que se incardinan en esa secuencia por la que discurre el drama de Viriato -renuncia de éste a aniquilar el ejército de Serviliano, aceptación por el Senado de una "pax aequa", inmediata revocación de esa paz por el Senado a instancias del nuevo gobernador y traición de un grupo de partidarios de Viriato- han sido interpretadas en formas divergentes, ya por los autores antiguos, y, desde luego, por los modernos, tratando de explicar a veces las aparentes incoherencias por recurso a argumentos de tipo moral, como el de la generosidad de Viriato, el de la gratuita violación de la "fides" por parte de Roma 0 el de la corruptibilidad de los traidores que asesinaron al caudillo. $Y$ también se ha pretendido minimizar las ventajas obtenidas por la coalición de Viriato en la paz de Serviliano suponiendo que Roma se habia limitado a conceder tierras para el asentamiento sin una independencia o soberanía sobre las mismas bajo un título jurídico $u$ otro ${ }^{\text {? }}$. Sin embargo, al plantear la cuestión en términos de estricto pragmatismo, las fluctuaciones que presenta la actitud de las partes en conflicto parecen justificables. Lástima que el conocimiento demasiado somero que tenemos de esos hechos y la incertidumbre en que nos movemos a la hora de interpretar con precisión algunos datos políticos o jurídicos fundamentales en relación con los mismos nos impidan verificar hasta qué punto fue, en efecto, un lance de la fortuna lo que impidió a Viriato convertirse en un Rómulo de Hispania.

Una primera clave para entender el asunto es sin duda la actitud de Roma con respecto a la expansión territorial por la Península en el momento de la consolidación del poder militar de Viriato. Parece muy verosímil la apreciación de Knapp ${ }^{8}$ en el sentido de que los romanos

bridge, 1968; H. DUYVENDAK, "Restraining regulations for Roman officials in the Roman provinces", Symbolae Van Oven, Leiden 1946, págs. 333-348.

Respecto de los años que van desde el 168 al 100 a.C., no es posible establecer una estimación en cifras de las rentas obtenidas por los romanos en la Península, porque faltan los datos oportunos. De todos modos, las escasas alusiones al botín parecen indicar que era bastante inferior al obtenido anteriormente, to cual se ha explicado sobre la base de que en la época inicial las ciudades indigenas habían entregado unas riquezas atesoradas durante largo tiempo, y luego ya, una vez despojadas de sus reservas, sólo pudieron pagar en razón de lo obtenido cada año, que no era, en general, demasiado. Es posible, incluso, que en algún momento por esos años Hispania costara dinero a Roma, y que ésa fuera una de las causas del intento de explotar los yacimientos mineros del noroeste, que debe de estar detrás de la expedición de Bruto el Galaico más allá del rio Lete.

7 Vease H. GUNDEL, "Viriato. Lusitano, caudillo en las luchas contra los romanos, 147139 a.C.", Caesaraugusta, 1968, págs. 175-198; idem, "Probleme der römischen Kampftührung gegen Viriatus", en Legio VII Gemina, León 1970, págs. 111-130.

${ }^{8}$ R. C. KNAPP, op. cit., pág. 29 y ss. 
consideraban a la sazón el Betis como una adecuada línea defensiva para la protección del territorio situado al sur del río, que era el que por entonces les interesaba realmente, porque de él obtenían grandes beneficios; las posiciones de Castellum Ebora, Gades, Italica, Ilipa, Castra Gemina, Decumana, Castra Postumiana, Calpurniana e lliturgis, a las que vendrían a sumarse Hispalis y Corduba, confirmarían en términos generales esa impresión, y en el mismo sentido apunta la ubicación de las acciones militares desarrolladas por los gobernadores de la Ulterior en las primeras décadas del siglo II a.C., que, o bien corresponden a la zona del valle del rio o, en todo caso, contribuyen indirectamente a la pacificación del área meridional. No se aprecia una iniciativa de ampliación territorial, $y$, aunque parece que Roma consigue de un modo u otro el control de la margen derecha del Betis, la aparente falta de posiciones militares al norte del río apunta a una estabilización de las conquistas. La ofensiva a gran escala de los lusitanos, que se inicia a mediados del siglo II y revela la vulnerabilidad de la línea del Betis, habría sido, según Knapp, el factor determinante de un replanteamiento de la frontera meridional, que se tradujo finalmente en una iniciativa clara de expansión hacia el norte. Con todo, en las primeras fases de este proceso, Roma, condicionada quizá por las necesidades militares de otros frentes, parece haber mantenido una actitud fundamentalmente defensiva, creyendo que el problema podria solventarse a base de operaciones de castigo contra ciudades y reductos hostiles, 0 del aniquilamiento de las tropas indígenas que se le oponian. El punto de inflexión entre esa actitud y la decisión de ampliar el territorio formalmente sometido es la paz de Serviliano, último intento, a lo que parece, de mantenerse en la línea del Betis.

Otra clave de la mayor importancia es la identificación étnica, social y geográfica de los elementos integrados en el bando de Viriato, y aquí sí tenemos que confesar una grave deficiencia de la documentación en nuestro haber, no sólo por falta de datos sino porque algunos de los que tenemos no son fehacientes ${ }^{9}$. El conjunto de las fuentes romanas de contenido historiográfico muestra que Viriato llegó a convertirse en un personaje de leyenda, $y$, por otra parie, hay que contar con la natural tendencia de la historiografia nacional a rehabilitar la imagen de los gobernadores provinciales, que con frecuencia se sirvieron del juego sucio en la defensa de sus intereses, públicos unas veces, estrictamente personales, otras. Todas estas desviaciones y adherencias han tenido que adulterar las noticias recibidas, viniendo a sumarse esta limitación a la passim.

${ }^{9}$ Cf. FHA IV, págs. 107 y ss.; H. GundeL, "Viriato..." o.c. passim; "Probleme...", o.c. 
que constituye de suyo el déficit de la información y nuestra incapacidad para identificar geográficamente muchas de las ciudades que, con nombre o sin él, se mencionan en las campañas de Viriato. Como es bien sabido, no estamos en condiciones de determinar quiénes eran los lusitanos que comandaba el caudillo, es decir, de qué zonas procedian, cuál era su extracción social y cuál su relación política con el jefe, al margen de la puramente militar. $Y$, por supuesto, la cuestión se complica todavía más cuando pasamos a la consideración de los elementos y núcleos de población no lusitanos, claramente turdetanos algunos de ellos, que llegaron a sumarse a su causa. Otro factor inaprehensible, en fin, es el de las conexiones de Viriato con áreas indígenas peninsulares no lusitanas. El grueso de la información sólo permite esbozar en términos bastante hipotéticos la composición y el carácter del bando al que se enfrentaron los romanos en las guerras de Viriato.

Sabemos que los asi llamados por las fuentes "lusitanos " habian intervenido varias veces con anterioridad en el territorio situado al sur del Betis, habiéndose supuesto que lo hicieron en calidad de mercenarios al servicio de los movimientos de resistencia contra el dominio romano que se habian fraguado en la zona ${ }^{10}$. Sabemos también que tenían una apetencia ancestral de asentamiento en las ricas tierras del sur y sospechamos que !legaran a instalarse en algunos puntos aprovechando coyunturas favorables, aunque ignoramos si fueron siempre evacuados de ellas o llegaron eventualmente a permanecer, mezclados o imbricados con las poblaciones allí existentes e integrados en el dominio romano. El hecho es que para Roma constituían una amenaza de penetración y razia, lo que nos invita a suponer que sus reductos más próximos se encontraban ubicados en las áreas montañosas de Sierra Morena, una enorme fortaleza natural situada en la gran franja comprendida entre el Anas y el Betis que, en expresión de Knapp, constituía a la sazón una "buffer zone" tangencial al territorio realmente incorporado al dominio romano. Desde Sierra Morena se abrian en abanico las tierras indigenas peninsulares no conquistadas, con las que era fácil para Viriato establecer todo tipo de contactos.

Los antecedentes señalados y la implicación en la causa de Viriato de una serie de núcleos urbanos importantes de la Turdetania sugiere que existía una conjunción de intereses entre los lusitanos y las ciudades

10 Véase G. ChIC Garcia, "Consideraciones sobre las incursiones lusitanas en Andalucía«, Gades, 1980, págs. 15-25.

11 O.c. págs. 32. 
sometidas del sur, sobre la base de que una acción unitaria que lograra la independencia frente a Roma podría resultar beneficiosa para las dos partes: los lusitanos podrian establecerse en las tierras apetecidas, y los otros se verían libres del yugo económico que los oprimía. La presencia muy probable de poscritos procedentes de esas ciudades al lado de $\mathrm{Vi}$ riato contribuiria a reforzar esos lazos. Ahora bien, si el bando de Viriato tenia, en efecto esa doble componente, hemos de admitir que su causa contaba con un factor potencialmente reforzador y potencialmente debilitador, lo que vendría a justificar las grandes fluctuaciones de la guerra y los bandazos del Senado en sus decisiones frente a la misma. La coalición con las ciudades indigenas, que podría extenderse a otras regiones hispanas sometidas, conferia viabilidad a la causa de Viriato, la hacía crecer y le otorgaba unas posibilidades razonables de victoria definitiva; sin embargo, eran las ciudades y no las tropas lusitanas móviles las que verdaderamente sufrian el castigo de los romanos, de suerte que las derrotas del caudillo, o incluso la posibilidad de llegar a una paz ex aequo, tendrian que debilitar esos fuertes apoyos, que se identificarian a sí mismos como los elementos perdedores del conclicto. De ahí que la balanza de Viriato subiera y bajara brusca y repetidamente, aun cuando no fuera él mismo ni sus fieles lusitanos los que se vieran directamente amenazados ${ }^{12}$.

El balance final de todas estas consideraciones nos lleva a señalar tres hechos: el primero, que la capacidad de resistencia y de subversión de Viriato era una amenaza muy importante para el dominio romano en la Península; el segundo, que esa capacidad estaba afectada por factores internos de inestabilidad que Roma podia capitalizar; $y$, el tercero, que la persona de Viriato era un elemento coordinador insustituible, hasta el punto de que su neutralización o su muerte debian de aparecer a los ojos de los romanos como la clave determinante de la suerte del conflicto.

No tendría, por tanto, que resultar tan extraño el hecho de que Viriato renunciara a destruir el ejército de Serviliano cuando pudo hacerlo,

${ }^{12}$ Esa aparente versatilidad de las ciudades aparece reflejada en la fábula del hombre maduro casado con las dos mujeres, la joven y la vieja, que según Didoro (33.7.5), habria referido Viriato a los habitantes de una ciudad llamada Tuca para convencerles de que debian decantarse claramente por uno de los dos bandos. Al margen de la procedencia de esa fábula (Véase J. C. Bermejo BarRera, Mitología y mitos de la Hispania prerromana, 2 , Madrid 1986, págs. 45 y ss.) y de la credibilidad de su atribución a Viriato, no cabe dudar de que su inclusión en la fuente de referencia obedece a una circunstancia real en relación con la consistencia del bando lusitano. Las alternativas propuestas para la identificación de esa ciudad la sitúan en todo caso en la margen izquierda del Betis. 
$y$, desde luego, no hay por qué interpretar tal decisión como un impulso de generosidad; el azar, la fortuna a la que alude Floro, le brindaba al fin una conyuntura favorable a la consumación de unas ambiciones personales que en ese momento parecían contar con una base relativamente sólida. En teoría, se exponia al riesgo de que el Senado no ratificara el acuerdo establecido en campaña por el «imperator»y recurriera al expediente que utilizaría no mucho después en la paz de Mancino ${ }^{13}$, lo que habría dejado a Viriato con las manos vacias. Se podria pensar que el lusitano no contó con esa posibilidad o que decidió jugarse su suerte a una sola carta, pero el hecho es que el tratado fue sellado, y la moderna historiografía se ha preguntado repetidamente por qué ${ }^{14}$. Los fuertes apoyos de Serviliano entre la oligarquía romana, que habrían intentado por todos los medios evitar al gobernador las desastrosas consecuencias sobre su persona derivables de la desautorización del acuerdo, han sido señalados como causa determinante, y también se ha pretendido restar toda importancia a las concesiones hechas a Viriato, limitándolas a una simple autorización de asentamiento para sus lusitanos en las tierras que apetecian.

Por desgracia, los términos del acuerdo, lacónicamente registrados por Apiano, se nos presentan afectados de ambigüedad. No es imposible, de hecho, que consistiera tan sólo en incluir a Viriato en la nómina de los «amici populi Romani» y en permitir el asentamiento de sus partidarios en un territorio bajo el dominio romano. En tal caso no resultaría demasiado difícil el entender cómo consiguieron los adalides de Serviliano convencer al Senado para que sancionara favorablemente la paz, porque el tratado resultaría ventajoso para los romanos. En su nueva condición de "amicus p.R.» ${ }^{15}$ Viriato quedaba incapacitado para prestar

13 I.e. Ia aplicación analógica de la "noxae deditio" a casos en los que un general romano hubiera concluido con el enemigo una "sponsio" en unos términos considerados como vejatorios o claramente perjudiciales para Roma por el Senado. El "sponsor" era juzgado, y, si su defensa no lograba imponerse, era entregado al enemigo como compensación de la negativa de sellar el acuerdo. Ct. Livio 9.8.9,10; Plutarco, Graco 7; Cicerón, De off. 3.30 De orat. 1.40; 2.32. Véase C. PHILLIPSON, The International Law and Custom of Ancient Greece and Rome, Londres 1911, I, págs. 368; E. TAUBLER, Imperium Romanum, Berlín 1913, págs. 138 y ss.; P. FREZZA, “Le forme federative e la struttura dei rapporti internazionali nell'antico diritto romano «, Stud. Doc. Hist. luris, 1939, págs. 181 y ss.

${ }^{14}$ Véase H. GundeL, “Viriato...", o.c. págs. 186 y ss.; R. KNAPP, o.C. pág. 42.

15 No es unánime la interpretación aportada por los especialistas sobre el contenido de la "amicitia" dentro del derecho público romano ni sobre su condición sustantiva o adjetiva con respecto al concepto de "tratado", pero es difícil negar que la paz y la neutralidad fueran, tácita o expresamente, condiciones inherentes a tal institución; ésa es la doctrina de E. TaubleR, Imperium Romanum, op. cit., pág. 44 y ss. De un modo similar $\mathrm{R}$. DE Martino, Storia della Costituzione Romana, vol. 2. Nápoles 1973, pág. 19 y ss. El desarrollo 
su apoyo a cualquier enemigo de Roma, lo que garantizaba potencialmente la pacificación del territorio sometido, bloqueando, además, la posible intervención de los lusitanos de él dependientes en eventuales acciones de expansión protagonizadas por los romanos; y, a su vez, los belicosos lusitanos, que parecian el agente desestabilizador, al menos en el sur, se convertirían en súbditos generadores de beneficios para la propia Roma. Por otra parte, si los lusitanos desarraigados eran los únicos que sacaban alguna ventaja del armisticio, y las ciudades implicadas en la causa de Viriato resultaban virtualmente defraudadas por el caudillo, éste perdería toda posibilidad de volver a protagonizar en el futuro una acción hostil contra el dominio romano de la naturaleza de las llevadas a cabo con anterioridad.

Ahora bien, una interpretación tan maximalista de la paz de Serviliano no resulta, en principio, convincente, no sólo porque cuesta trabajo creer que Viriato haya reducido hasta tal extremo sus exigencias cuando se encontraba en una posición virtualmente fuerte, sino porque hace difícil el encontrar las razones que hubiera podido esgrimir Servilio Cepión muy poco después para convencer al Senado de la necesidad de revocar el tratado, sobre todo teniendo en cuenta que no hay la menor constancia en las fuentes de que Viriato o los suyos se hubieran mostrado inconsecuentes con los compromisos adquiridos. $Y$ tampoco se compaginarian demasiado bien esas cláusulas con el calificativo de "pax in aequibus condicionibus facta" o de "deformis" que atribuye Livio ${ }^{16}$ a la de Servi-

monográfico más completo del tema es el de B. PARADISI, L'amitié internazionale. Les phases critiques de son ancienne histoire. Acad. de droit internazionale, 1951.

Los jurisconsultos romanos parecen distinguir con claridad entre "amicitia" y "societas", de modo que, salvo mención expresa en el tratado, el "amicus" no tendría obligación de luchar al lado de Roma (cf. Dig. 49.15.5/2 y 49.15.19/3. Véase también P. FrezzA, "Le forme federative e la struttura dei rapporti internazionali nell'antico diritto romano", Stud. Doc. Hist. luris, 1938, págs. 363-427, y, desde luego, W. DAHLHEIM, Struktur und Entwicklung des römischen Völkerrechts, Munich 1968, págs. 163-269, aunque no trata el caso de Viriato. La posición más restrictiva respecto del contenido propio de la "amicitia" es quizá la de A. Heuss, Die Völkerrechlichen Grundlagen der römischen Aussenpolitk in republikanischer Zeit, Klio Beiheft 31. Por su parte, R. KNAPP, op. cit. págs. 38-39 y 46-47 postula una amplia utilización de la "amicitia" por parte de Roma durante la primera fase de su presencia en la Península, considerando que las comunidades ligadas por ese vinculo contraían unas obligaciones activas análogas a las de los súbditos de Roma. Creemos que tiene razón al apuntar que tal condición no implicaba la libertad de un modo necesario, pero el hecho de que la "amicitia" admitiera unas cláusulas que la aproximaban a la "societas", o que podian convertirla en un titulo de dominio, no implica que ello ocurriera en todos los casos.

${ }^{16}$ Livio, Perioche 54: "Q. Fabius procos, rebus in Hispania prospere gestis labem imposuit pace cum Viriatho aequis condicionibus facta". Idem, Epit. Oxy., 185: "Q. Fabius Maximus a Viriatho devictus deformen cum hostibus pacem fecit». El calificativo que atri- 
liano, a no ser que el historiador se haya dejado influir descompasadamente por la tendencia a justificar una conducta romana contraria a los principios de la "fides", como lo fue la de la ruptura unilateral de esa paz ${ }^{17}$. Pero, además, la expresión utilizada por Apiano no parece la más adecuada a semejante contenido ${ }^{18}$. Habría bastado el término $\varepsilon " \chi \varepsilon ı$ ivpara indicar el asentamiento en régimen de posesión de las tierras: ¿por qué se utiliza también äpxeıv? Sería preciso forzar un tanto la interpretación para argumentar que se alude aquí a la posibilidad de regirse por las propias leyes, otorgadas normalmente a las comunidades que se integran en el dominio romano a través de una "deditio" y consiguen una permanencia como tales comunidades, puesto que en este caso el punto de partida para los lusitanos de referencia sería el de una ocupación meramente militar. La verdad es que las palabras de Apiano invitan más bien a pensar que se reconoció la independiencia de las ciudades y territorios que en ese momento controlaba Viriato por no haber sido reconquistados por las armas romanas, lo que cuadraria mucho mejor con una paz «en-

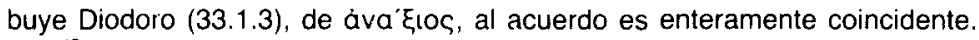

17 En esta época Roma se había liberado de los condicionamientos morales en política internacional, hasta el punto de que el principio contenido en el cius fetiale" de considerar "nefas", es decir, ingrata a los dioses y, por ende, impia, toda guerra que no tuviera como móvil y como fin la defensa de la propia patria y, por extensión, la de los aliados, no parece haber jugado ya el más mínimo papel a partir del s. II a.C. El primer atentado teórico el «ius fetiale" parece haberse producido precisamente por influencia de Grecia, y consiste en la introducción del concepto de "guerra defensiva". Se trata en esencia de considerar como justo y lícito el declarar la guerra a alguien a quien se considera como un enemigo potencial para el futuro, evitando con ello que llegue verdaderamente a serlo. (Cf. C. NiCOLET, Rome et la coquête du Monde méditerranéan, París 1978, pág. 892). Este tipo de guerra no tiene como fin el ampliar el propio territorio, pero sí puede tenerlo como medio, con lo cual el resultado es el mismo. Todo este nuevo desarrollo del código bélico de los romanos justifica la cancelación de la paz con Viriato sin necesidad de desvirtuar hechos o términos. Véase también M. Holleaux "Preventing warfare", en Imperialism in the Roman Republic, ed. E. S. GRUEN, Nueva York 1970. E. BAdIAN (Roman Imperialism in the Late Republic, Oxford 1967, págs. 10-11) considera como una prueba de que la ley se habia desvirtuado ya en el s. II el hecho de que las fuentes no aludan a ella en absoluto, 10 cual parece bastante convincente, a pesar de la opinión de C. Nicolet (op. cit., pág. 890), que no es del todo acorde. Las especulaciones que se encuentran incidentalmente en las fuentes sobre el carácter justo o injusto de una determinada guerra no implican, creemos, una pervivencia del «ius fetiale", ya que se pueden explicar dentro de la corriente filosófica grecorromana. En el fondo parece haber un pragmatismo como determinante de las actuaciones, que se limita a mantener una dialéctica formal con la moralidad y la filosofía, en el sentido de que todo lo que interesa en un momento dado puede ser justificable y justificado.

Sobre el desarrollo del imperialismo romano en lo tocante a la valoración moral de las actuaciones, vease A. W. LiNTOTT, "Imperial expansion and moral decline in the Roman republic", Historia, 1972, págs. 626-638, y R. W. BANE, "The development of Roman Imperial attitudes and the Iberian wars", Emerita, 1976, págs. 409-420.

18 Apiano, lber. 69. 
tre iguales". Es posible que tal renuncia no fuera demasiado importante ni cuantitativa ni cualitativamente para Roma en ese momento, y que las ventajas de la neutralización de Viriato, que incluían en todo caso una presumible reducción de los gastos militares, resultaran en verdad interesantes, sobre todo si los romanos no estaban por entonces especialmente interesados en la expansión territorial hacia el norte del Betis.

Esta interpretación más equilibrada de la paz de Serviliano permite entender mejor el desarrollo subsiguiente de los hechos. No podemos establecer, por supuesto, las verdaderas razones que impulsaron a Servilio Cepión, hermano y sucesor de Serviliano en el gobierno de la Ulterior, a asumir una iniciativa tan fuerte y arriesgada como lo era la de declarar la guerra a Viriato, para lo cual recabó de modo insistente la necesaria autorización del Senado. Tal vez no tuviera otro móvil que la simple ambición personal, la aspiración al botín y al triunfo, que le estaba vedada en una provincia pacificada ${ }^{19}$. Pero también es posible que considerara honestamente como una amenaza para Roma a largo o a medio plazo el reconocimiento de un poder independiente en esa zona ${ }^{20}$. Cepión pudo entender que desde su nueva situación política Viriato era capaz de ir acrecentando su ámbito de dominio a costa de la gran área hispánica que tenía a sus espaldas, la que no estaba todavía sometida al control romano y, por lo tanto, era susceptible de ser anexionada por cualquiera de las dos partes sin violación de la «amicitia». El crecimiento

${ }^{19}$ Una de las lacras del imperialismo romano era, sin duda, esa paradoja que hacia deseable y necesaria frecuentemente la guerra a los gobernadores provinciales para dar lustre a sus respectivas carreras. No hay duda de que provocaron muchas veces las hostilidades y realizaron operaciones de castigo injustificadas, acuciados por esos móviles inconfesables, que en ocasiones coincidian con el interés de la tropa. Hasta tal punto eran necesarios los triunfos militares para justificar la promoción personal que se inventaban o se magnificaban gratuitamente, exhibiéndose despojos que no habian sido conquistados al enemigo sino comprados (Cf. Catón fr. 58, 97 y 94); es el procedimiento de la "ambitio", alternativa de la "virtus", que consistía en conseguir la gloria de un modo tortuoso, aunque no necesariamente ilegal. Véase R. PAYNE, Roman Triumph, Londres 1962, pág. 60 y ss.

${ }^{20}$ El temor al crecimiento del enemigo es una interpretación aportada a algunos comportamientos hostiles por parte de Roma, dificiles de justificar. Es la tesis de F. E. Adcock en relación con el caso de Cartago ( Fear of Carthage and Irrationality", en Imperialism in the Roman Republic, op. cit., págs. 77-84), que sigue en este punto la línea de M. HoLLEAux (Rome, la Grèce et les monarchies hellénistiques, Paris 1921), quien sostuvo que la conquista de Grecia por parte de Roma se habia producido por casualidad, es decir, como resultado de una serie de expediciones que, lejos de obedecer a un plan expansionista preestablecido, se habian organizado por pura necesidad y sin otra intención que la de restar fuerza a un enemigo al que se consideraba capaz de amenazar seriamente a la propia Roma. La declaración de guerra contra Macedonia en el 200 a.C. era para Holleaux, como la decisión de destruir Cartago para Adcock, casos limite en los que esa actitud obedecia a unos temores imaginarios. 
del poder de Viriato iría multiplicando en potencia los costos militares requeridos para reducir ese núcleo independiente, si ello llegaba a hacerse necesario, a la obediencia de Roma, de modo que la decisión adoptada en el 141 tenía una gran trascendencia. Quizá viera Servilio Cepión en el "amicus p.R.» a ese Rómulo de Hispania evocado por Floro.

Bien es verdad que para concretar este punto tendriamos que saber exactamente cuál era el tipo de vínculo político que unia a Viriato con sus dependientes y con los elementos dominantes de los núcleos indigenas que le obedecian, y bien es verdad que no lo sabemos. Está claro que lo habían reconocido como caudillo en las acciones de guerra, y es a esa condición de jefe militar coyuntural a la que responden por lo general los términos que le aplican las fuentes. Diodoro desliza el voca-

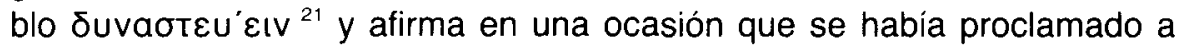
sí mismo ouvaótnc, poco después de haber dicho que había sido ele-

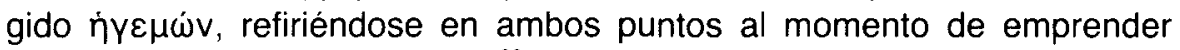
la guerra contra los romanos ${ }^{22}$. El término ouváotns es ambiguo, e, incluido como está en una antítesis retórica frente a $\lambda$ notrń («bandido»), nos llevaría todo lo más a pensar en un reyezuelo atrincherado en una pequeña ciudad, por oposición al jefe de un grupo errabundo de depredadores. La imagen de Diodoro es demasiado convencional, y, a nuestro juicio, no aporta nada para establecer la condición política de Viriato en el momento de la consolidación de su poder. En cuanto a la concesión al caudillo del título de "amicus p.R.», tampoco resulta clarificadora, habida cuenta de que, desde el punto de vista constitucional romano, tiene un carácter estrictamente personal, donde no se encuentra una diferenciación entre la esfera privada y la pública; ocasionalmente se concede a reyes y príncipes, pero el hecho de que un determinado beneficiario disfrute de un poder político en su comunidad no garantiza que sea, en efecto, un rey. Por lo demás, faltan en las fuentes vocablos latinos o griegos verdaderamente significativos de la realeza en relación con Viriato, lo que nos impide pensar que hubiera alcanzado algo más que unos poderes fácticos de difícil concreción dentro de las categorías constitucionales romanas. $Y$ señalemos, en fin, que de ese enigmático término äpXeiv no se hace en Apiano sujeto a Viriato sino "a los que estaban con él» o «bajo sus órdenes».

\footnotetext{
21 Diodoro 33.21.

22 Id. 33.1,1-3.
} 
Es muy probable, por tanto, que Cepión se enfrentara a un germen de "regnum», no a un "regnum» propiamente dicho, lo que justificaria a la vez su preocupación por destruirlo y su confianza en que era capaz de hacerlo. El desarrollo en el Senado de la urgente e inmediata gestión de Servilio Cepión para conseguir que se rompiera la paz indica, por un lado, que el poder de Viriato aparecia como fundamentalmente carismático y, por otro, que se consideraba fuerte. De acuerdo con el relato de Apiano $^{23}$, el Senado se resiste en un principio a abrir las hostilidades,

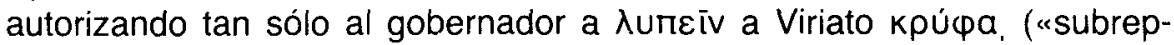
ticiamente»). No es fácil concretar el sentido exacto de $\lambda u \Pi \varepsilon i v$ en este caso, pero deberíamos excluir cualquier ataque o provocación contra las personas o las cosas protegidas por el acuerdo, puesto que ello habría equivalido a quebrantarlo. $O$ bien se sugirió a Cepión que intentara ganarse por una vía más o menos diplomática a los elementos que constituían la fuerza de Viriato, o bien el término empleado por Apiano es un tanto eufemístico, y lo que realmente se hizo fue inducir una conspiración destinada a deshacerse del caudillo. Su muerte liquidaría la "amicitia" suscrita, y posiblemente se tenía la impresión de que no habría un heredero político.

El caso es que Cepión no debió de encontrar viabilidad en esas alternativas, puesto que parece haber insistido a ultranza en que se le permitiera adoptar la de la intervención militar abierta. La ruptura unilateral del acuerdo sin mediar provocación alguna perjudicaba la imagen de Roma, pero no es menos cierto que era también por sí misma un golpe psicológico contra el poder de Viriato, puesto que restaba esperanza a la posibilidad de consolidar la situación alcanzada. No obstante, la capacidad de resistencia del caudillo era grande, como lo prueba la complejidad de las acciones y movimientos de Serviliano en esta guerra y la aparente implicación en ella de la provincia Citerior. La documentación relativa a esas campañas plantea muchas dificultades de detalle ${ }^{24}$, pero la clave del desenlace parece estar en las ciudades meridionales. Es claro que Viriato no está en condiciones de defender ese frente, desde un primer momento, y ello probablemente porque en el territorio que teóricamente lideraba no se habian llegado a establecer unos mecanismos de organización interna que permitieran aunar esfuerzos con rapidez y eficacia para socorrer a los puntos más vulnerables. En el mismo comienzo de la guerra se aprecia una regresión en la situación de Viriato, que lo lleva virtualmente al punto de partida, por más que siga contando con la ven-

${ }^{23}$ Apiano, Iber. 70.

${ }^{24}$ Véase H. Gundel, Oo. $c C$. 
taja que le confiere la movilidad de sus tropas, hasta el punto de resultar poco menos que imposible el llegar a acorralarlo. Los movimientos militares de Cepión por el oeste parecen destinados a impedir que se crezca, obstaculizando sus conexiones con esas zonas ${ }^{25}$; en cuanto a sus intentos de negociación, que reflejan las fuentes de un modo muy confuso, es probable que pretendieran en realidad atraer al caudillo hasta una situación vulnerable y deteriorar su imagen, con vistas a encontrar una coyuntura favorable para liquidar definitivamente una guerra que podría dilatarse hasta dejar al gobernador en una situación desairada al término de su mandato.

La historiografía romana se divide a la hora de dar su versión sobre el mecanismo que actuó en la muerte de Viriato ${ }^{26}$. De acuerdo con la mayoría de los autores, Cepión habría sobornado por propia iniciativa con abundantes dádivas a unos embajadores que habrian acudido de buena fe a negociar la paz; por el contrario, la tradición recogida por Diodoro sostiene que fueron los traidores quienes urdieron el plan, convenciendo a Viriato para que los enviara como embajadores ante Cepión y ofreciéndose entonces a asesinar al caudillo a cambio de su seguridad personal. Lo cierto es que en las dos versiones la responsabilidad del romano es próximamente la misma, como lo es también la de los asesinos. Únicamente, el dato que aporta Diodoro sobre la pertenencia a Urso de los tres traidores y la mención de Apiano en el sentido de que, cuando se presentaron ante Cepión con la misión cumplida éste les permitió conservar lo que ya les había dado, pero los remitió a Roma para las demás

${ }^{25}$ Apiano (lber. 70) menciona una campaña de Cepión contra los Vetones y los Galaicos consistente en una operación de saqueo, bajo la cual se ha querido ver también una búsqueda de recursos en la zona minera del noroeste, naturalmente por vía de botín y pillaje. Se supone asimismo que, al margen de otros posibles procedimientos de guarnición de la zona lusitana, habia establecido un campamento más o menos permanente, los "castra Servilia". Hay que advertir, sin embargo, que, a pesar de la seguridad con que Schulten atribuyó a Servilio Cepión esta iniciativa, todo lo que sabemos de tal campamento es lo que nos dice Plinio en un pasaje de su Nat. Hist. (4.117): “Coloniae... Norbensis/ Caesarina cognomine: contributa sunt in eam Castra Servilia, Castra Caecilia». Su agregación a la colonia Norba Caesarina (sobre la que véase U. LAFFl, Adtributio e Contributio, Pisa 1966. pág. 133 y ss.) indica que estaba próximo a ella, aunque no sabemos dónde, porque, a diferencia de los "Castra Caecilia", los "Servilia" no han sido todavía localizados. Se ha supuesto que deberian de estar muy cerca uno de otro ambos campamentos, en razón de la mención de Ptolomeo (2.5.8), que denomina Kaikilia Gemellinon a Castra Caecilia, lo cual parece implicar que se habian unido en esa época, pero esto no es más que una hipótesis. $Y$ es igualmente una hipótesis su atribución a Servilio Cepión y, consecuentemente, la fecha de su fundación, por más que resulte coherente con nuestras noticias sobre el control militar de la Lusitania establecido por los Romanos en torno a los años correspondientes al gobierno de Cepión y al fin de la resistencia lusitana.

${ }^{26}$ Véase H. GundeL, "Viriato...» o. c. pág. 191 y ss. 
peticiones ${ }^{27}$, parecen justificar una conjura que contrasta con la reacción de los que rodeaban a Viriato ante su muerte ${ }^{28}$. Viriato seguía siendo fuerte entre los suyos, pero debia de haber perdido definitivamente la adhesión de las ciudades del sur, que estaban a la total merced de Roma y sufrian los costos de la represión, sin esperanza ya de mejorar. Es verosímil, por tanto, que los tres individuos de Urso, si en verdad eran de allí, se dispusieran a asesinar a Viriato no ya para garantizar su seguridad personal, que no estaba a la sazón especialmente amenazada, - para conseguir una ganancia fácil, sino para proporcionar a su ciudad unas condiciones favorables, logrando al mismo tiempo reintegrarse a sus hogares. Ese pudo haber sido el contenido de las peticiones a que alude Apiano, y ésa la razón de que fueran enviados a Roma para solicitarlas. La muerte de Viriato se habría gestado, entonces, de un modo, por así decirlo, natural; porque era un error del caudillo contar entre sus incondicionales a quienes lo habian perdido todo y no tenían ya nada que ganar a su lado. Que, si alguna vez habia llegado, en efecto, Viriato a ser un Rómulo de Hispania en potencia, no lo era ya con seguridad cuando fue apuñalado.

27 Diodoro, 33. 21; Apiano, Iber. 71.

${ }^{28}$ Véase Apiano, Iber. 72; Diodoro, 33. 21; Livio, Perioche, 54. 